莕

SSCL-539

Superconducting Super Collider Laboratory

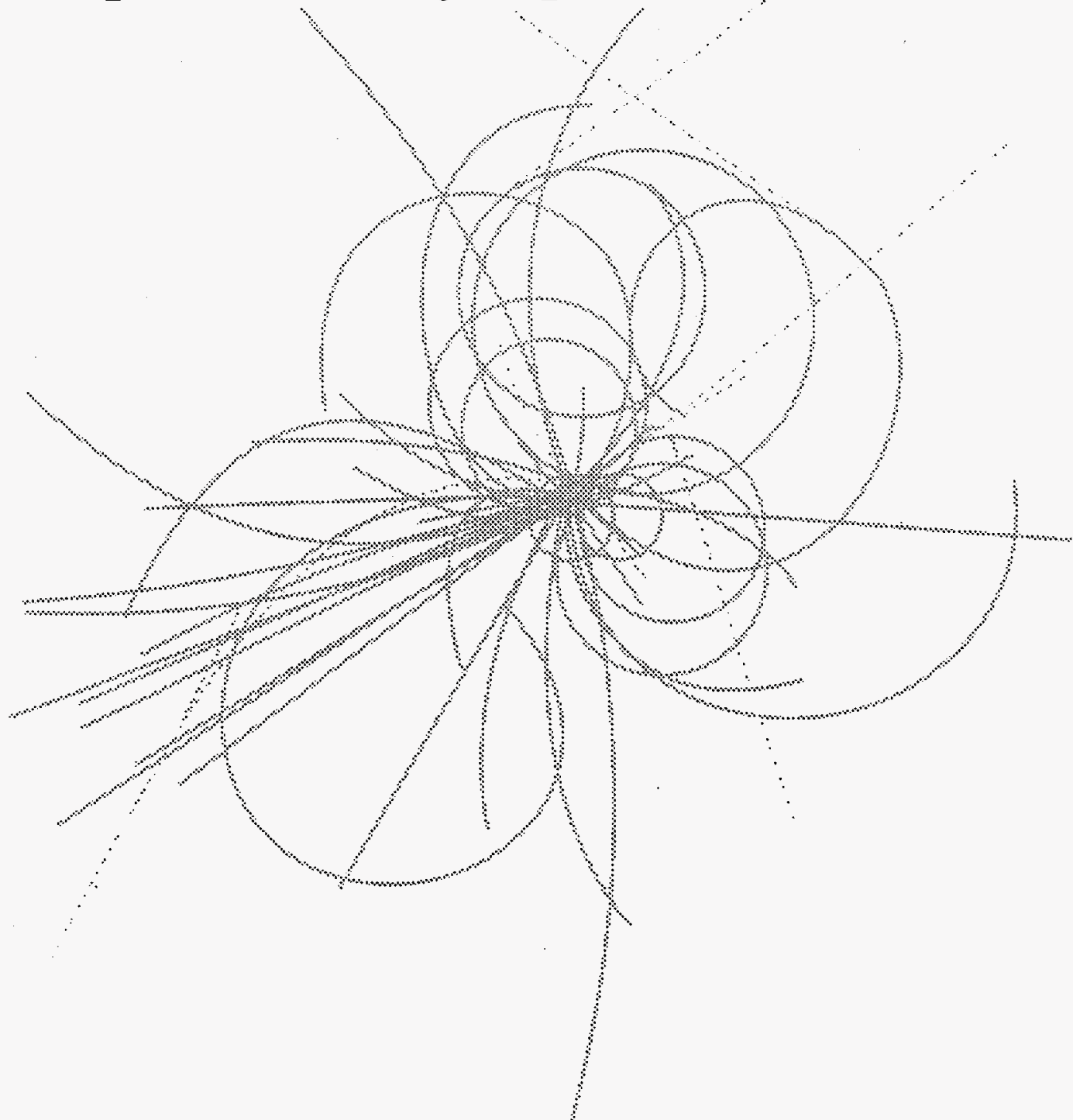

High Frequency Breakdown Voltage

Thanh Duy Chu

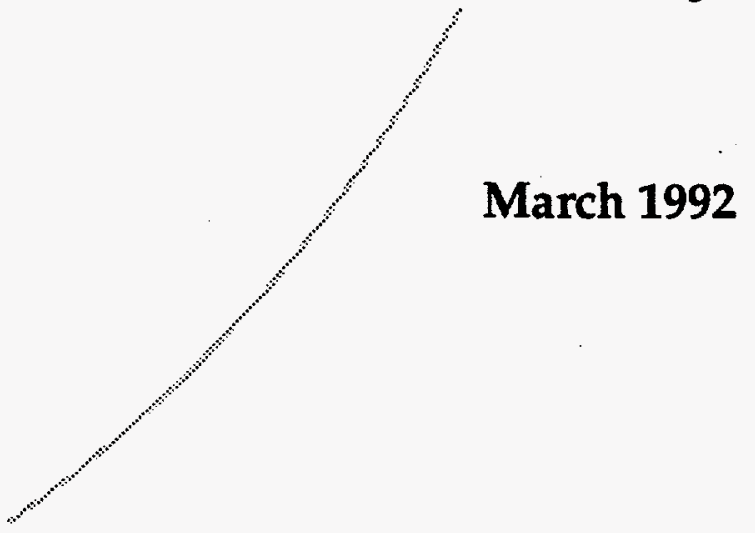

APPROVED FOR RELEASE OR PUBLICATION - O.R. PATENT GROUP BY..... \& .....DATE. 16.20 .25 


\title{
High Frequency Breakdown Voltage
}

\author{
Thanh Duy Chu \\ Superconducting Super Collider Laboratory* \\ 2550 Beckleymeade Ave. \\ Dallas, TX 75237
}

March 1992

* Operated by the Universities Research Association, Inc., for the U.S. Department of Energy under Contract No. DE-AC35-89ER40486. 



\title{
High Frequency Breakdown Voltage
}

\author{
Thanh Duy Chu
}

\begin{abstract}
This report contains information about the effect of frequency on the breakdown voltage of an air gap at standard pressure and temperature, $76 \mathrm{~mm} \mathrm{Hg}$ and $0^{\circ} \mathrm{C}$, respectively. The frequencies of interest are $47 \mathrm{MHz}$ and $60 \mathrm{MHz}$. Additionally, the breakdown in vacuum is briefly considered.

The breakdown mechanism is explained on the basis of collision and ionization. The presence of the positive ions produced by ionization enhances the field in the gap, and thus determines the breakdown. When a low-frequency voltage is applied across the gap, the breakdown mechanism is the same as that caused by the $\mathrm{DC}$ or static voltage. However, when the frequency exceeds the first critical value $f_{c}$, the positive ions are trapped in the gap, increasing the field considerably. This makes the breakdown occur earlier; in other words, the breakdown voltage is lowered. As the frequency increases two decades or more, the second critical frequency, $f_{c e}$, is reached. This time the electrons start being trapped in the gap. Those electrons that travel multiple times across the gap before reaching the positive electrode result in an enormous number of electrons and positive ions being present in the gap. The result is a further decrease of the breakdown voltage. However, increasing the frequency does not decrease the breakdown voltage correspondingly. In fact, the associated breakdown field intensity is almost constant (about $29 \mathrm{kV} / \mathrm{cm}$ ). The reason is that the recombination rate increases and counterbalances the production rate, thus reducing the effect of the positive ions' concentration in the gap.

The theory of collision and ionization does not apply to the breakdown in vacuum. It seems that the breakdown in vacuum is primarily determined by the irregularities on the surfaces of the electrodes. Therefore, the effect of frequency on the breakdown, if any, is of secondary importance.
\end{abstract}

\section{DISCLAIMER}

This report was prepared as an account of work sponsored by an agency of the United States Government. Neither the United States Government nor any agency thereof, nor any of their employees, makes any warranty, express or implied, or assumes any legal liability or responsibility for the accuracy, completeness, or usefulness of any information, apparatus, product, or process disclosed, or represents that its use would not infringe privately owned rights. Reference herein to any specific commercial product, process, or service by trade name, trademark, manufacturer, or otherwise does not necessarily constitute or imply its endorsement, recommendation, or favoring by the United States Government or any agency thereof. The views and opinions of authors expressed herein do not necessarily state or reflect those of the United States Government or any agency thereof.

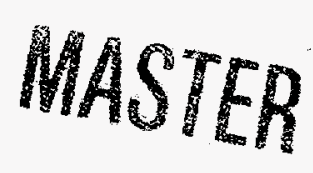





\section{DISCLAIMER}

Portions of this document may be illegible in electronic image products. Images are produced from the best available original document. 


\section{CONTENTS}

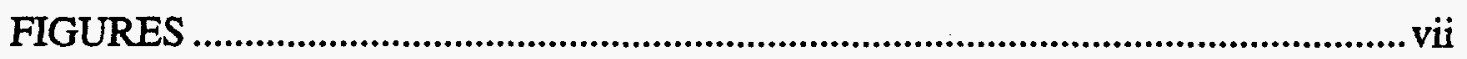

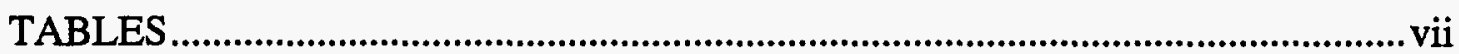

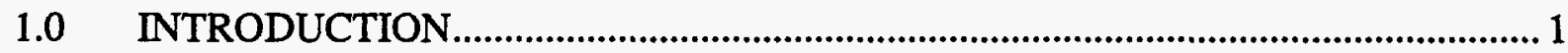

2.0 THE STATIC OR DC BREAKDOWN MECHANISM........................................... 1

3.0 THE EFFECT OF FREQUENCY ON THE BREAKDOWN VOLTAGE .................... 2

3.1 The Critical Frequency..................................................................................... 2

3.2 The Critical Gap Width..................................................................................... 2

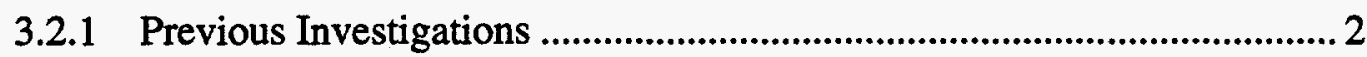

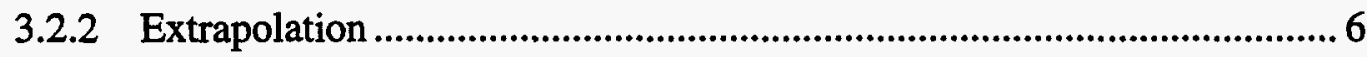

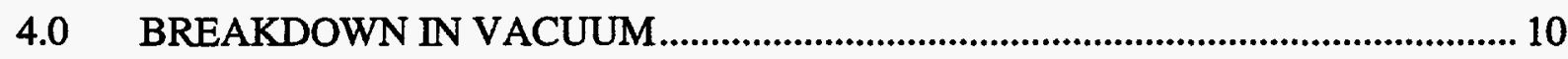

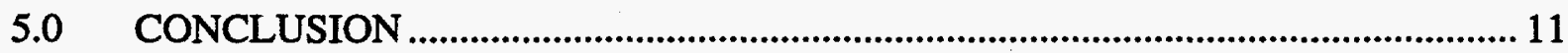

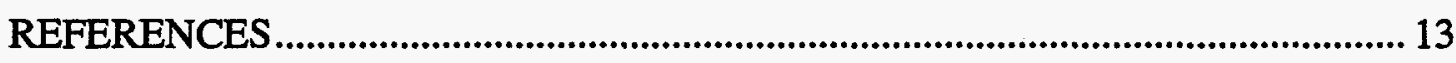

APPENDIX 



\section{FIGURES}

1. Distribution of Charge Carriers in an Avalanche and Their Contribution to the

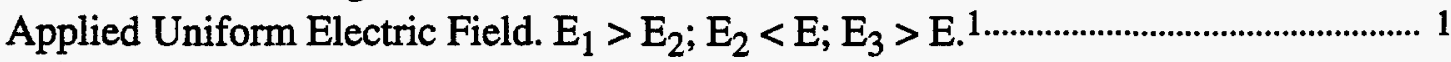

2. Gap Width versus Breakdown Voltage Obtained by Miseré and Luft. (10-cmKugeln Symmetrische Anordnung: 10-cm-sphere gap symmetrically arranged.).......... 3

3. Breakdown Voltage Curves in Nitrogen as a Function of Gap Length between Spheres of 2.0-cm Diameter............................................................................................. 3

4. Gap Width versus Breakdown Voltage Obtained by Reukema....................................... 4

5. Variation of Ultra-High-Frequency Breakdown Voltage with Gap Width at Atmospheric Pressure........................................................................................................5

6. Electrical Breakdown Strength of Air at Ultra-High Frequencies. ${ }^{3}$ …….............................5

7. Ratio of High-Frequency Breakdown Voltage to Static Breakdown Voltage as a Function of Frequency for an Air Gap. 4

8. Variation of Ultra-High-Frequency Breakdown Voltage with Gap Width at Atmospheric Pressure (with Extrapolated Values). 9

9. Electrical Breakdown Strength of Air at Ultra-High Frequencies (with Extrapolated Values). ${ }^{3}$

10. Variation of Critical Gap Width with Frequency (Calculated by Pim and Extrapolated).

\section{TABLES}

1. Gap Widths and Breakdown Voltages for Eight Points on Curve KA........................7

2. Critical Gap at Given Frequencies in the Range of $47-100 \mathrm{MHz}$.............................. 8 


\subsection{INTRODUCTION}

The breakdown voltage between electrodes in air at atmospheric pressure is discussed when the frequency of the applied voltage varies. The frequency range of interest is $47-100 \mathrm{MHz}$, especially the two frequencies of $47 \mathrm{MHz}$ and $60 \mathrm{MHz}$. Additionally, the breakdown in vacuum is briefly mentioned. However, before the effect of frequency on the breakdown voltage is examined, it is advisable to have an overview of the static or DC breakdown mechanism.

\subsection{THE STATIC OR DC BREAKDOWN MECHANISM}

Assume a uniform field $E$ is applied to the electrodes, and somehow there is a free electron in the gap. Under the influence of the field $E$, the electron moves toward the anode, gaining more and more energy on the way. If the field $E$ is strong, the electron has enough energy to ionize an air molecule by collision, thereby freeing another electron. The second electron travels to the anode together with the first one, leaving behind it a positive ion. Then the two electrons collide with other air molecules, yielding even more electrons and positive ions. The process goes on and on. When the electrons reach the anode, they have a long tail of positive ions whose density is highest at the anode (Figure 1).

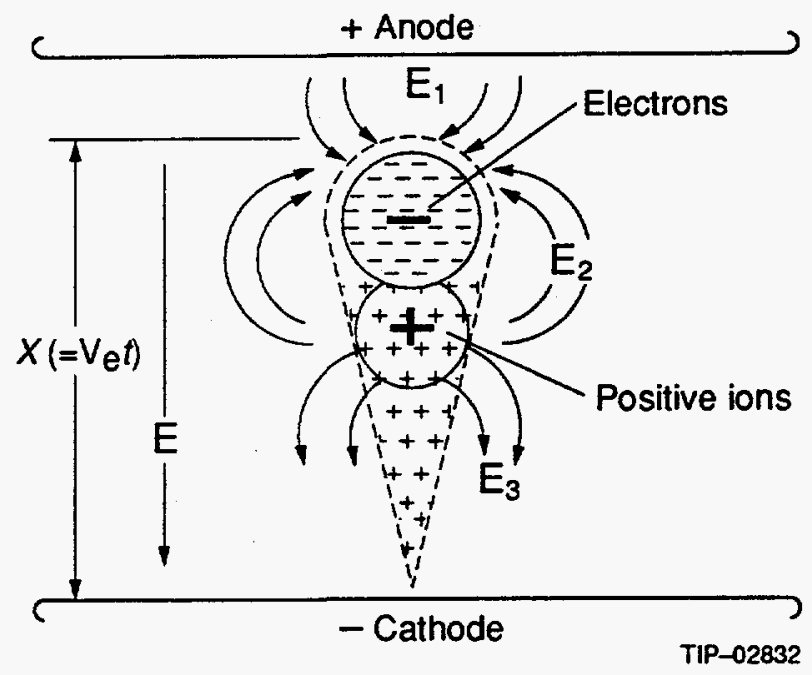

Figure 1. Distribution of Charge Carriers in an Avalanche and Their Contrlbution to the Applied Unlform Electric Field. $E_{1}>E_{2} ; E_{2}<E ; E_{3}>E_{1}{ }^{1}$

Note that an electron is much lighter than a positive ion, so the electron moves faster in the same field. Because most of the electrons produced are swept into the anode, the ionization of electrons alone cannot cause a breakdown. ${ }^{2}$

When the applied field is higher, positive ions are allowed to ionize the air modules by collisionproducing more electrons and positive ions-or to knock electrons out of the negative cathode. Those newborn electrons are enormous, and they in turn yield more electrons and ions through collision.

Being slower, the positive ions seem to be stationary while the electrons are crossing the gap. The ions then form a space charge near the anode. The field caused by this accumulation of positive ions increases the field in the gap. Consequently, the gap current grows rapidly and leads to breakdown. "... The criterion of breakdown may depend on the concentration of positive ions, rather than on the total number formed within the gap. As a result, the concentration of electrons in the electron avalanche will play a major part in the initiation of breakdown."3 


\subsection{The Critical Frequency}

When the frequency of the applied voltage varies, we have to consider the distances the positive ions and electrons can travel before the cycle reversal-that is, in a half cycle of the voltage. Before we go further, let's define mobility. The mobility of a positive ion is its velocity in an electric field. Mobility varies directly with the field intensity $E$, so the mobility constant is defined as the velocity in $\mathrm{cm} / \mathrm{sec}$ at atmospheric pressure and $0^{\circ} \mathrm{C}$ per $\mathrm{V} / \mathrm{cm}$ of electric field. A positive ion has the mobility constant of 1.32 , so in the field of $30,000 \mathrm{~V} / \mathrm{cm}$ it has the velocity of $30,000 \times 1.32$, or $39,600 \mathrm{~cm} / \mathrm{sec}$. However, the mobility of an electron does not vary directly with the field, so it does not have the mobility constant. Its mobility is a function of $E / p$, where $E$ is the field intensity, and $p$ is the pressure. According to Compton in Physical Review of 1923 , an electron has a velocity of $13,800,000 \mathrm{~cm} / \mathrm{sec}$ at $E$, equal to $30,000 \mathrm{~V} / \mathrm{cm}$. In the same condition, the electron moves 348 times faster than the positive ion in this example. ${ }^{2}$

As the frequency increases, a point is reached at which the ions cannot reach the cathode before this electrode reverses its polarity. The ions remain in the gap, and because the avalanche continues, they form a space charge with growing density. The space charge then distorts the field in the gap. According to the above breakdown criterion suggested by $\mathrm{Pim},{ }^{3}$ it is the space charge that lowers the breakdown voltage in comparison with the DC breakdown value. The frequency at which the breakdown voltage begins to decrease below the static value is called the first "critical frequency," $f_{c}$.

If the frequency is raised even more, another phenomenon occurs. At this time, the electrons themselves cannot have enough time to travel to the positive electrode in the half cycle. Assume one electron ionizes once for every thousand collisions with air molecules. Because the mean free path of an electron (the distance the electron travels before colliding with a molecule) at atmospheric pressure is about $0.00005 \mathrm{~cm}$, the electron will ionize 20 times per centimeter. The number of new electrons produced by that single electron is given by $e^{20 d}$, where $d$ is the gap width in centimeters. Because that electron cannot reach the positive electrode during the previous half cycle, it has to travel the distance of $d \mathrm{~cm}$ once more to reach the new positive electrode. It will produce a total of $e^{2 \cdot 20 d}$ new electrons and the same number of positive ions. The density of the already existing positive ions space charge will then be highly increased and will in effect distort the field in the gap considerably. Therefore, the breakdown voltage is expected to be lowered even more. The corresponding frequency is called the second "critical frequency," $f_{c e}$. With a further increase in frequency, however, the electrons become trapped in the gap, as do the positive ions, and the electrons cancel out the space charge of positive ions. In other words, the recombination rate goes up and finally counterbalances the production rate. This reduces the field intensity in the gap. Consequently, the breakdown voltage begins to rise toward the static value.

\subsection{The Critical Gap Width}

\subsubsection{Previous Investigations}

On considering the effect of the frequency on the breakdown voltages, researchers are also interested in the "critical gap" in which, at a given frequency, the high-frequency breakdown voltage begins to decrease below the static value as the gap width is increased. Experiments have shown the existence of this critical gap.

Misere and Luft, working on 10-cm-sphere electrodes at frequencies around $450 \mathrm{KHz}$, came up with the curves shown in Figure 2. For comparison, the breakdown values at $50 \mathrm{~Hz}$ are included on the graph. The critical gap is approximately $1.5 \mathrm{~cm}$. Note that gaps smaller than the critical gap have breakdown values almost identical to DC values. 4

Curves obtained by Bright showed the similar proofs of critical gaps when he studied short gaps in nitrogen. 5 (See Figure 3.) 


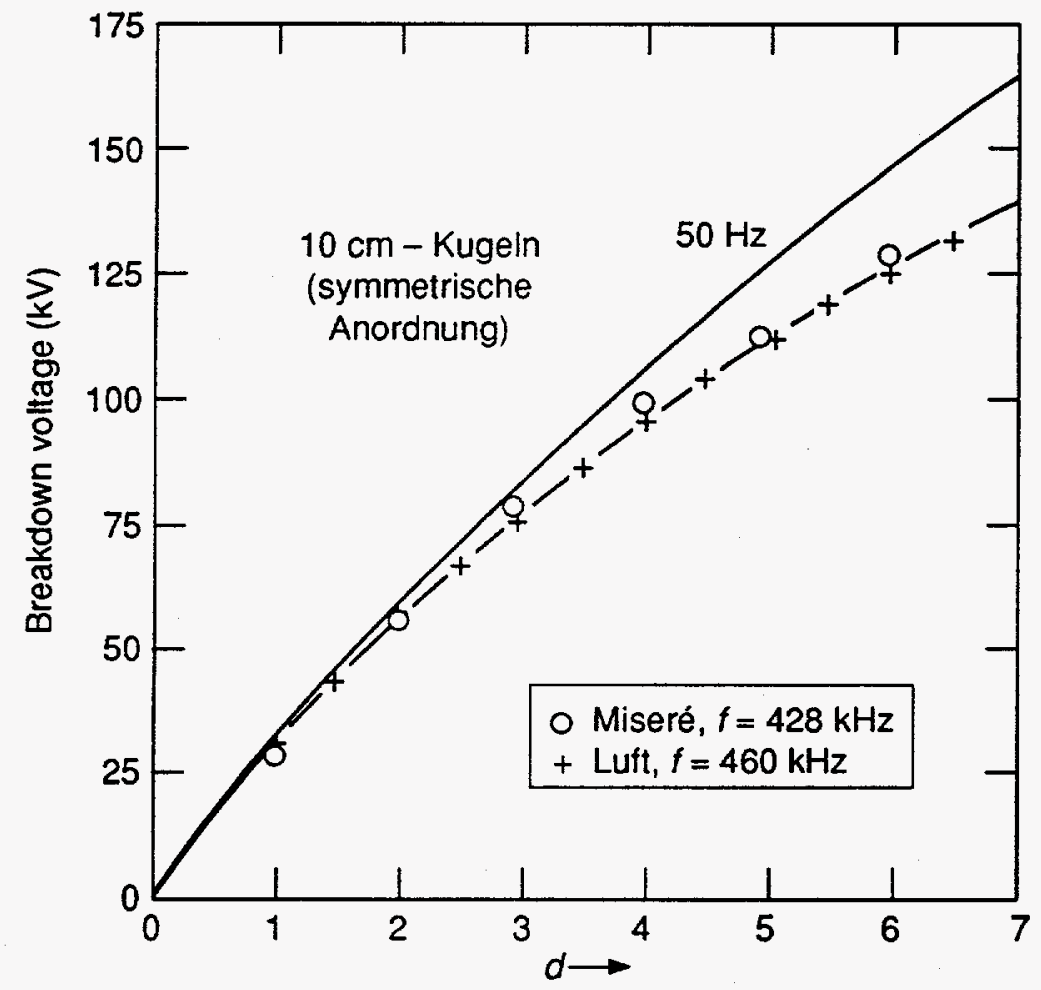

Gap width (cm)

TIP-02833

Figure 2. Gap Width versus Breakdown Voltage Obtained by Miseré and Lutt. (10-cm-Kugeln Symmetrische Anordnung: 10-cm-sphere gap symmetrically arranged.)

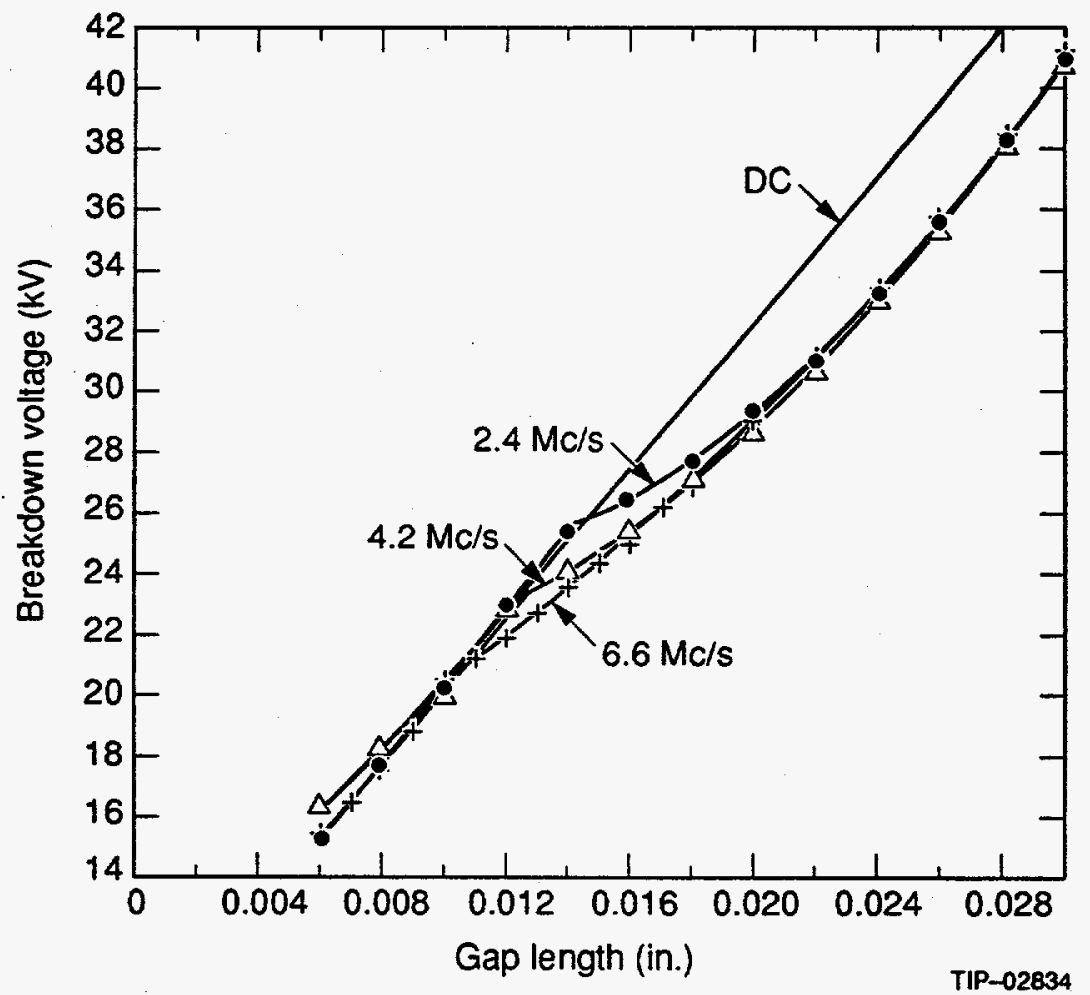

Figure 3. Breakdown Voltage Curves in Nitrogen as a Function of Gap Length between Spheres of 2.0-cm diameter. 
Recalling the explanation for the critical frequency in Section 3.1, we can reason in the same way for the effect on the breakdown values as gap width increases. At a given frequency, a point is reached where the gap is so long that positive ions cannot travel to the positive electrode during the half cycle of the voltage. They become trapped in this critical gap and form the space charge, the field of which increases the field in the gap; then the breakdown voltage begins to decrease from the static values. This critical gap width, $g_{c}$, is associated with the critical frequency, $f_{c}$. This gap is clearly shown in the experimental curves issued by Reukema. $^{2}$ (Figure 4).

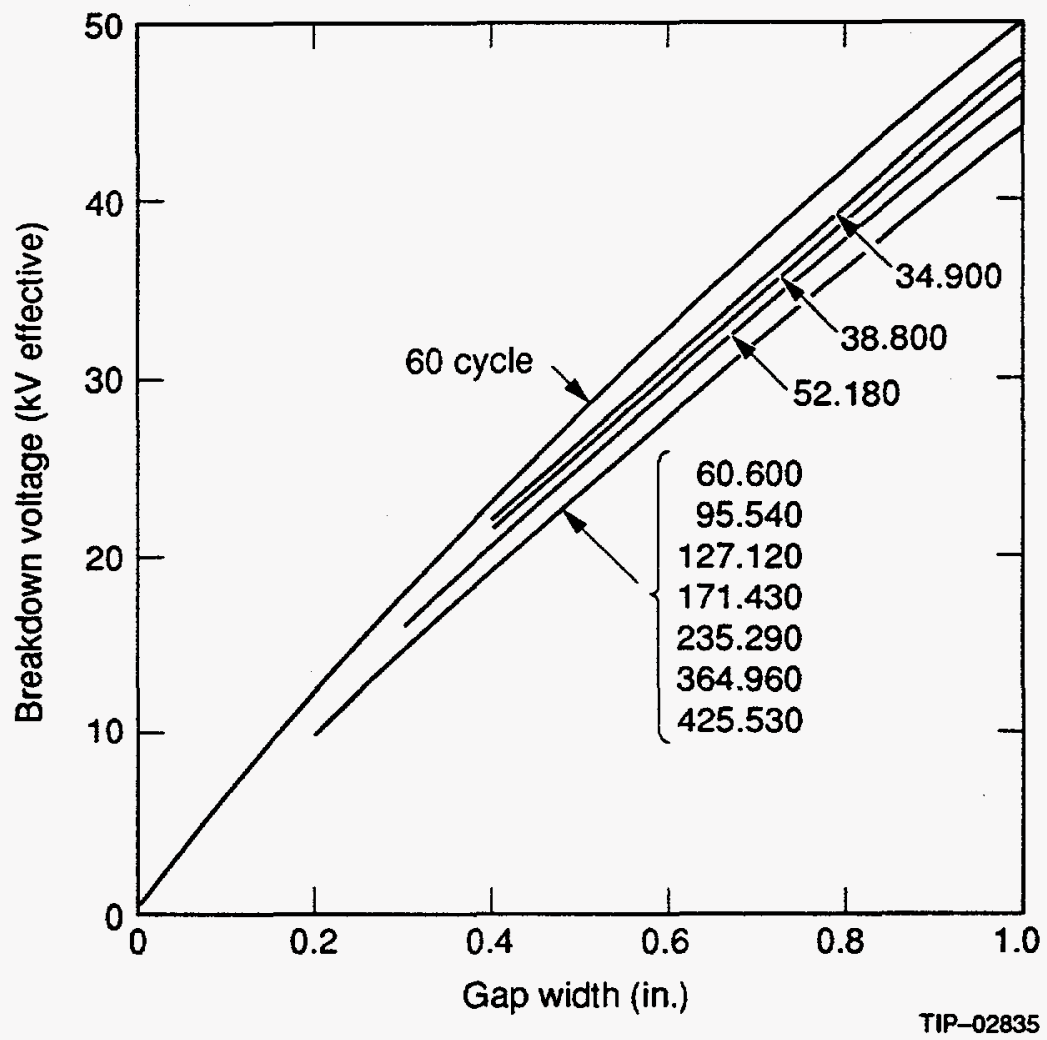

Figure 4. Gap Width versus Breakdown Voltage Obtained by Reukema.

Reukema has worked on gaps up to $2.5 \mathrm{~cm}(1 \mathrm{in}$.) in the range of $20-425 \mathrm{KHz}$. It is observed that there is not much change in the breakdown voltage versus frequency until it approaches $20 \mathrm{KHz}$. Then there is a gradual decrease in the breakdown values in the range of $20-60 \mathrm{KHz}$. However, there is little change as the frequency rises to $425 \mathrm{KHz}$, which is the highest test frequency. In fact, on the graph we find a single curve for the whole bunch of frequencies in the range of $60.6-425.530 \mathrm{KHz}$. In other words, the breakdown voltage increases with constant gradient as the gap width increases. (In this case the voltage gradient approximates $17 \mathrm{kV} / \mathrm{cm}$.)

As the gap width increases, the electrons in turn are caught in the gap. We expect further decrease in the breakdown value at the second critical gap, $g_{c e}$, which is associated with the critical frequency, $f_{c e}$. Indeed, in the above experiment Reukema ${ }^{2}$ also predicted that there would be further decrease in breakdown values at frequency equal to $6 \mathrm{MHz}$ for a 1-cm gap, which accounts for $f_{c e}$ and $g_{c e}$.

$\mathrm{Pim}^{3}$ has worked on parallel plane gaps up to $1 \mathrm{~mm}$ with a field of frequencies between $100 \mathrm{MHz}$ and $300 \mathrm{MHz}$ (Figure 5). Breakdown voltages versus gap width at various frequencies at atmospheric pressure are shown. Breakdown voltage follows the normal rising curve, which agrees quantitatively with the above values obtained by Reukema (10-15\% lower than the low-frequency values), until the critical gap is achieved. Then the breakdown voltage drops suddenly, passes a minimum, and finally rises with a constant gradient. 


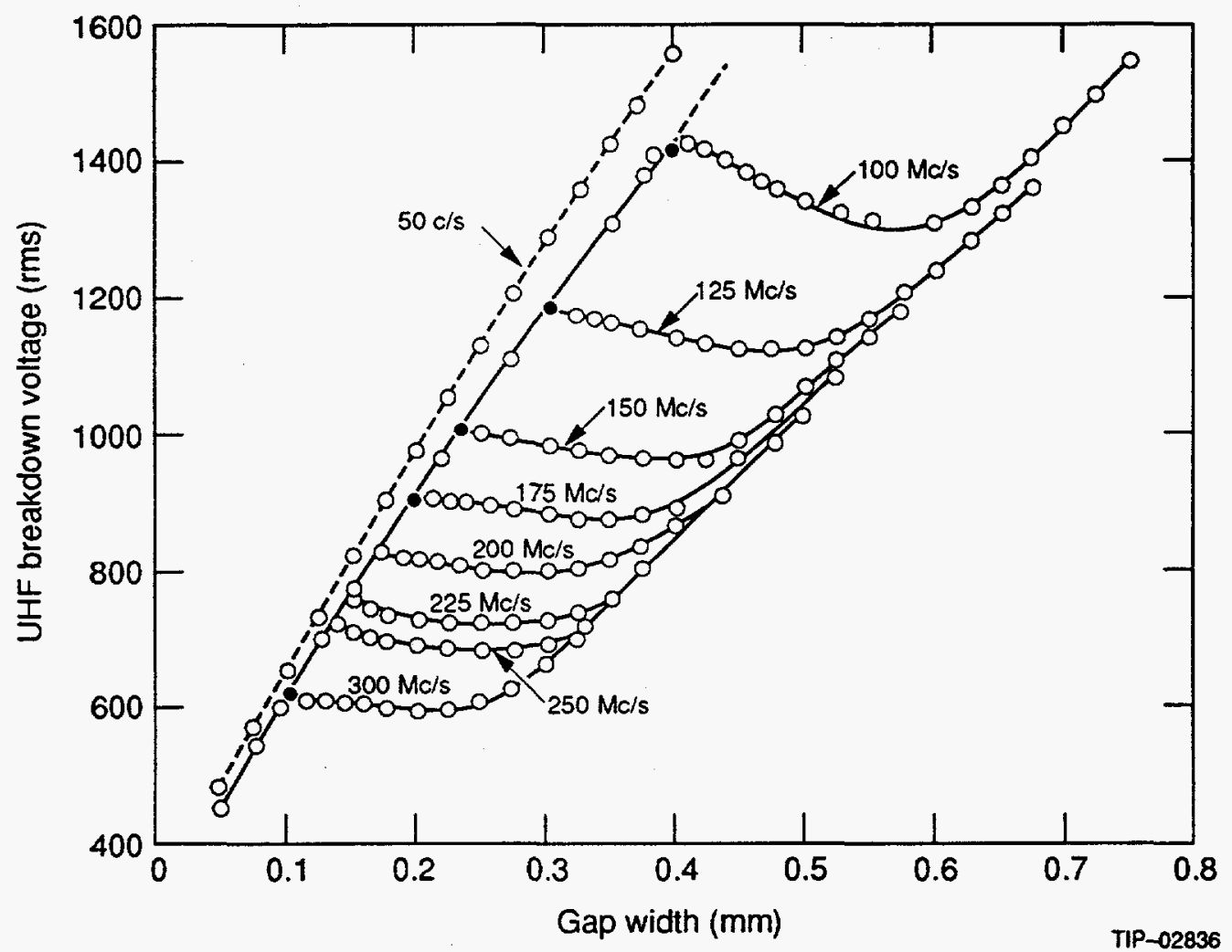

Figure 5. Variation of Ultra-High-Frequency Breakdown Voltage with Gap Width at Atmospheric Pressure.

The corresponding curves of breakdown field intensity versus the gap width are shown in Figure 6. Gaps smaller than the critical gap have a breakdown field $10-15 \%$ lower than the $50 \mathrm{~Hz}$ values. At the critical gap, the field decreases almost double, finally arriving at a constant value of $29 \mathrm{kV} / \mathrm{cm}$ as the gap increases at all frequencies. ${ }^{3}$

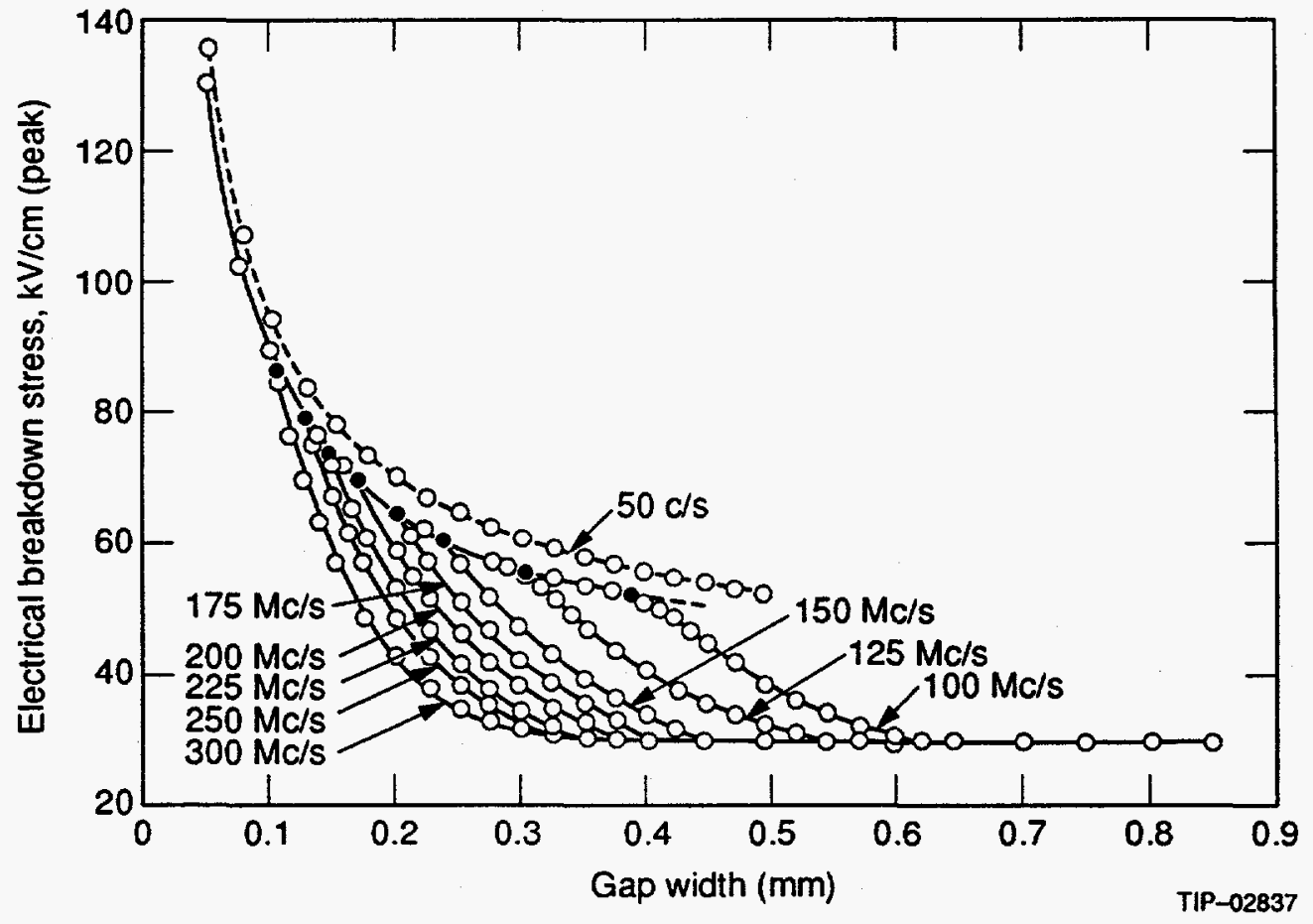

Figure 6. The Electrical Breakdown Strength of Alr at Ultra-High Frequencles. ${ }^{3}$ 
The above theory is further confirmed by the experiment of Rohde and Wedemeyer. They worked on 1-cm-sphere gap spacing $2 \mathrm{~mm}$ apart. The breakdown voltage is made relative to its value at $50 \mathrm{~Hz}$ for comparison (Figure 7).

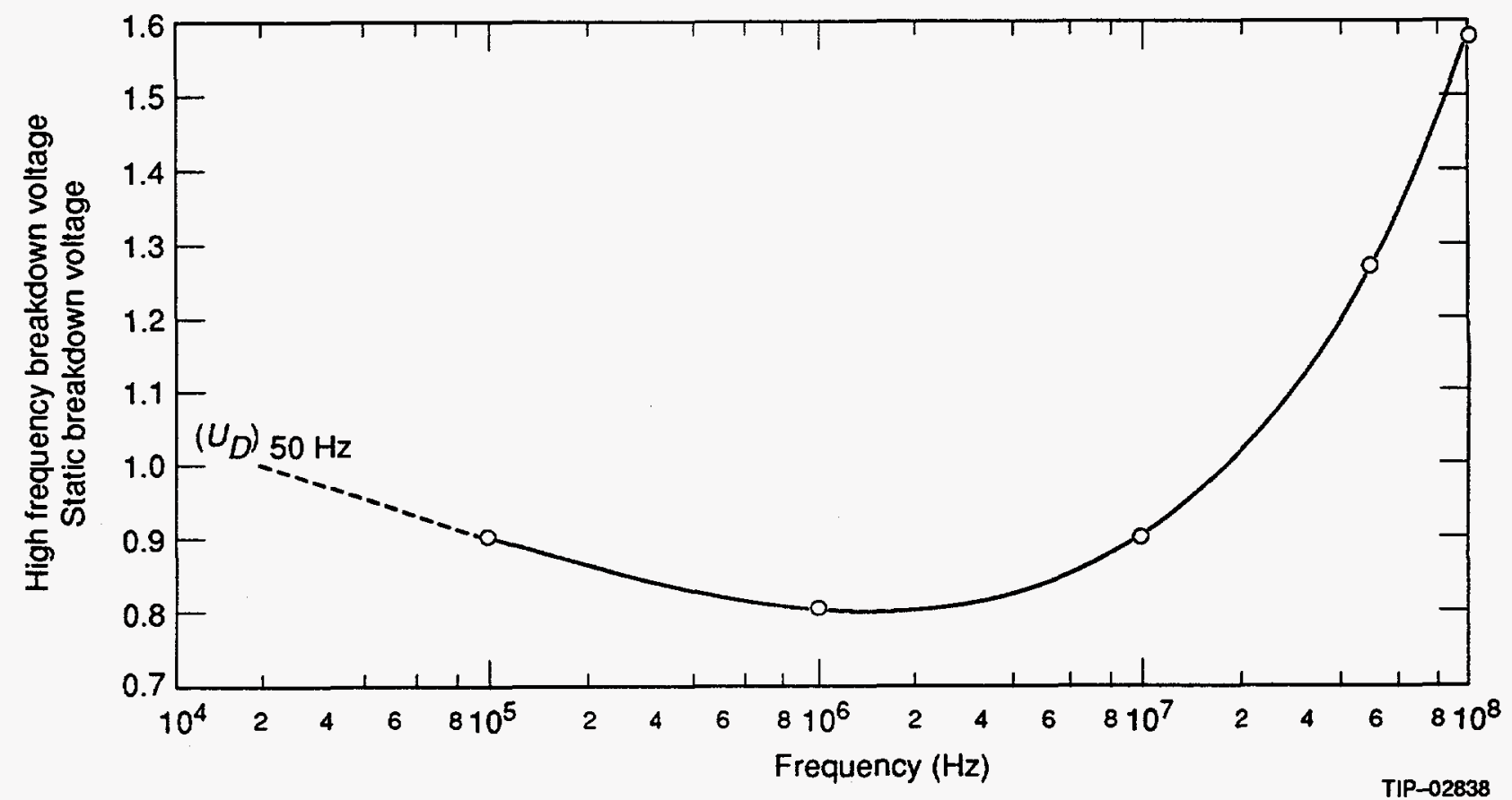

Figure 7. Ratlo of High-Frequency Breakdown Voltage to Static Breakdown Voltage as a Function of Frequency for an Air Gap. ${ }^{4}$

Two observations are worth noting:

1. Around $20-40 \mathrm{KHz}$ the breakdown potential starts reducing. This must be associated with the critical frequency, $f_{c}$.

2. When the frequency increases, as expected, the breakdown potential reduces further, passes a minimum at around $1 \mathrm{MHz}$, and rises toward the static value. Note that the breakdown voltage is finally becoming greater than the static value.

\subsubsection{Extrapolation}

Knowledge of the critical gap permits the calculation of the critical gaps in the frequency range of interest (47-100 MHz) from Pim's curves (Figure 5).

Analyzing the curve, we find that the critical gap, at a given frequency, must lie on the curve KA. In other words, the gap's coordinates will satisty the equation of the curve $\mathrm{KA}$. We are going to approximate a straight line for the curve KA using "the least square curve fitting" method based on empirical data from Pim's curve. We choose eight points on the curve KA: A, B, C, D, E, F, G, and K, corresponding to breakdown points at $100 \mathrm{MHz}, 125 \mathrm{MHz}, 150 \mathrm{MHz}, 175 \mathrm{MHz}, 200 \mathrm{MHz}, 225 \mathrm{MHz}, 250 \mathrm{MHz}$, and $300 \mathrm{MHz}$, respectively (Table 1 ). 
TABLE 1. GAP WIDTHS AND BREAKDOWN VOLTAGES FOR EIGHT POINTS ON CURVE KA.

\begin{tabular}{|c|c|c|}
\hline POINT & $\begin{array}{c}\text { GAP WIDTH } \\
(\mathrm{cm})\end{array}$ & $\begin{array}{c}\text { BREAKDOWN VOLTAGE } \\
(\mathrm{rms} \mathrm{V})\end{array}$ \\
\hline A & 0.040 & 1427 \\
B & 0.031 & 1200 \\
C & 0.240 & 1013 \\
D & 0.020 & 907 \\
E & 0.017 & 833 \\
F & 0.015 & 773 \\
G & 0.014 & 733 \\
K & 0.010 & 640 \\
\hline
\end{tabular}

A program in Fortran gives the equation of the straight line that most fits the curve KA:

$$
\text { Breakdown Voltage }\left(\text { in } \mathrm{rms} \text { V) }=26423.46 \text { gap }_{\mathrm{c}}(\text { in } \mathrm{cm})+375.948\right.
$$

The critical gap at a given frequency also matches the following equation given by Pim:

$$
g_{c e}=\frac{2 k E}{7 w p}\left[6-\sqrt{15-\frac{21 p^{2} B_{0}}{A E^{2}}}\right]
$$

where

$k=$ proportional factor between velocity and $(E / p)$

$v=k(E / p)$

$k=3.9 \times 10^{5}(\mathrm{~cm} / \mathrm{sec})(\mathrm{mm} \mathrm{Hg})(\mathrm{V} / \mathrm{cm})$

$E=$ peak electric field $(\mathrm{V} / \mathrm{cm})$

$w=2 \pi f$

$p=$ gas pressure (mm of mercury) ( $p=760 \mathrm{~mm} \mathrm{Hg}$ at atmospheric pressure)

$B=$ loss coefficient representing electron loss due to recombination, spread of electron radial outward. $B=0.0116$ in DC condition. ${ }^{3} B=0.0133$ at atmospheric pressure and $E=34 \mathrm{kV} / \mathrm{cm}^{3} B$ is proportional to gas pressure. Assume $B=0.0133$ in our calculation.

$A=$ empirical data $=1.58 \times 10^{-5}(\mathrm{~mm} \mathrm{Hg}) /(\mathrm{V} / \mathrm{cm})^{2}$.

Of course, we have:

$$
\text { Breakdown Voltage }=\frac{E g_{c e}}{\sqrt{2}}
$$

because the breakdown voltage value is an $\mathrm{mms}$ value, and $E$ is the peak value. 
A solution to $g_{c e}$ is obtained by solving the three simultaneous equations (1), (2), and (3). (See Table 2.) This is done in a program in Fortran using iteration methods as follows:

1. Guess a value for $E$ in $V / c m$.

2. Use this $E$ value to calculate $g_{c e}$ in Eq. (2).

3. Use this value of $g_{c e}$ to calculate the breakdown voltage in Eq. (1).

4. Use this value of breakdown voltage to calculate $E$ in Eq. (3).

5. Compare the value of $E$ in Step 4 and the guessed value in Step 1. If the difference is greater than 0.01 , let $E$ equal $E_{1}$, and repeat Steps 2-5.

TABLE 2. CRITICAL GAP AT GIVEN FREQUENCIES IN THE RANGE OF 47-100 MHZ.

\begin{tabular}{|c|c|c|c|}
\hline $\begin{array}{c}\text { FREQUENCY } \\
(\text { MHz) }\end{array}$ & $\begin{array}{c}\text { CRITICAL GAP } \\
(\mathrm{cm})\end{array}$ & $\begin{array}{c}\text { BREAKDOWN VOLTAGE } \\
\text { (rms V) }\end{array}$ & $\begin{array}{c}\text { BREAKDOWN FIELD } \\
\text { INTENSITY } \\
\text { (peak kV/cm) }\end{array}$ \\
\hline 47 & 0.064 & 2066 & 45.67 \\
50 & 0.060 & 1972 & 46.16 \\
60 & 0.051 & 1728 & 47.74 \\
70 & 0.045 & 1554 & 49.28 \\
75 & 0.042 & 1485 & 50.03 \\
80 & 0.040 & 1424 & 50.77 \\
90 & 0.036 & 1322 & 52.20 \\
100 & 0.033 & 1240 & 53.60 \\
\hline
\end{tabular}

Finally, we use the same method, "the least square curve fitting," to:

1. Establish the approximate line for the $50-\mathrm{Hz}$-breakdown voltage versus gap width in frequencies 47-100 MHz.

2. Establish the approximate line for the "limit" line $\mathrm{K}^{\prime} \mathrm{A}$ ' so that we can predict the gap range, at a given frequency, in which the breakdown voltage is reduced substantially.

All the parts of curves obtained by extrapolation are included on the original curves from Pim for comparison (Figures 8-10). 


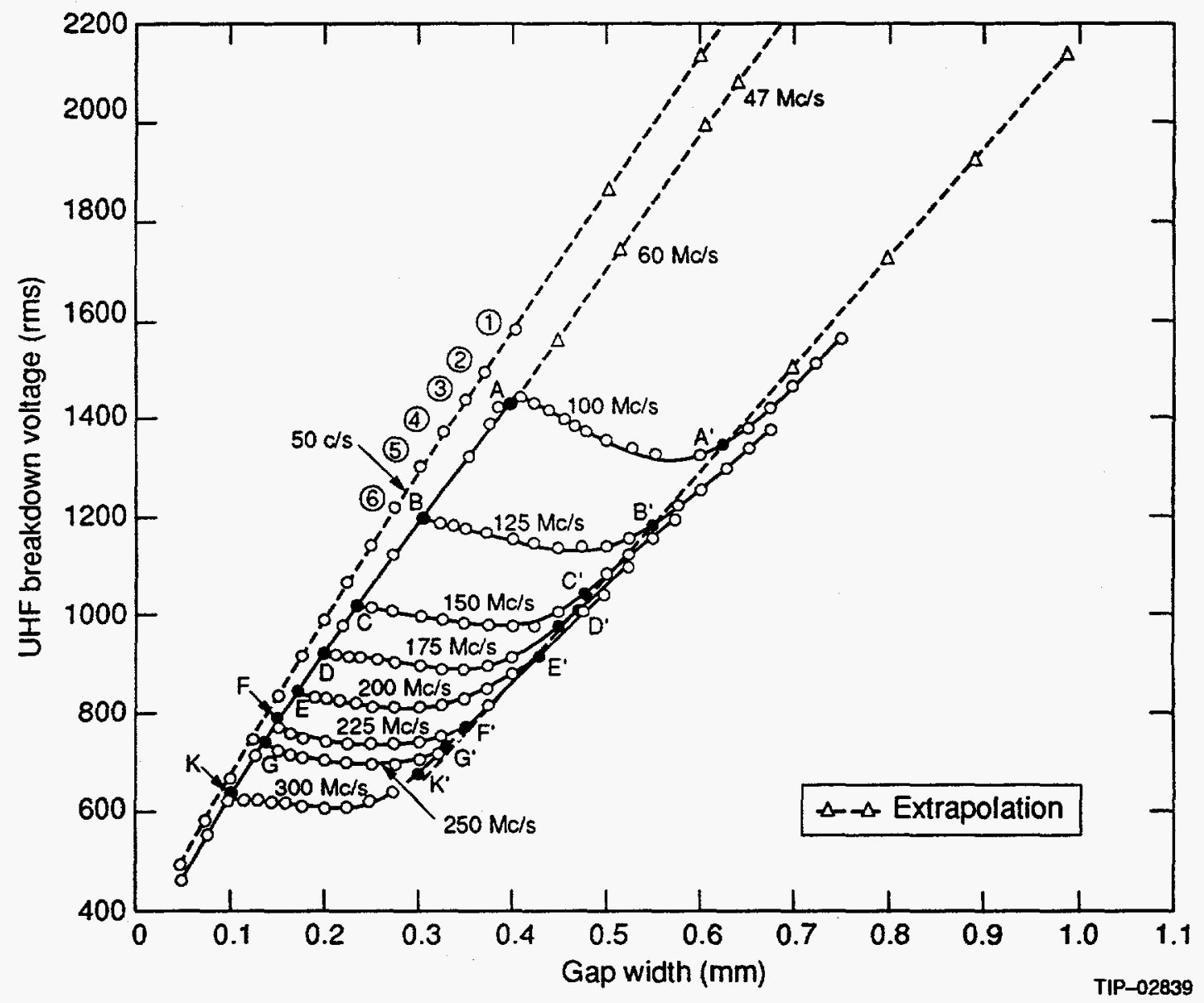

Figure 8. Variation of Ultra-High-Frequency Breakdown Voltage with Gap Width at Atmospheric Pressure (with Extrapolated Values).

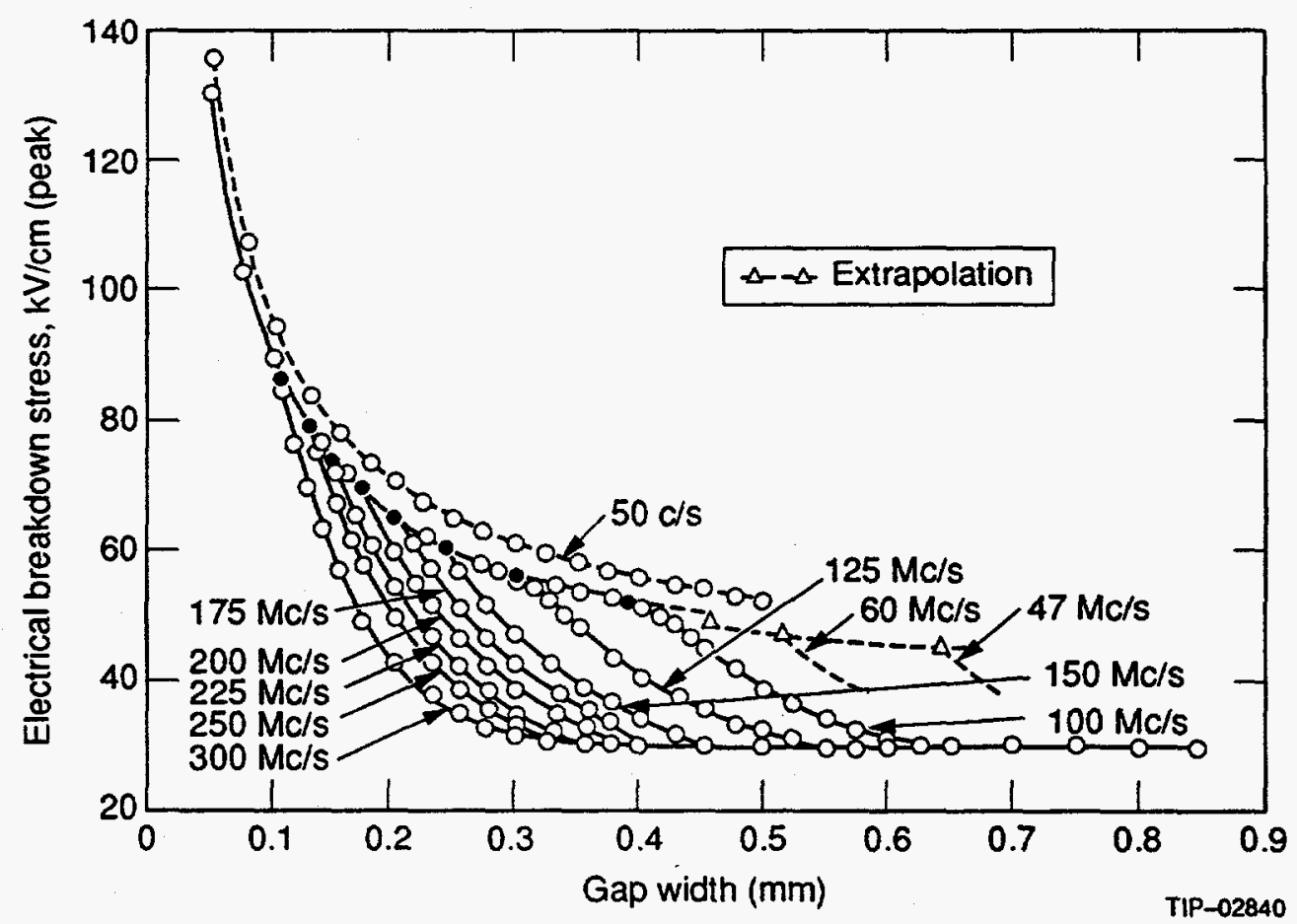

Figure 9. Electrical Breakdown Strength of Air at Ultra-High Frequencies (with Extrapolated Values). ${ }^{3}$ 


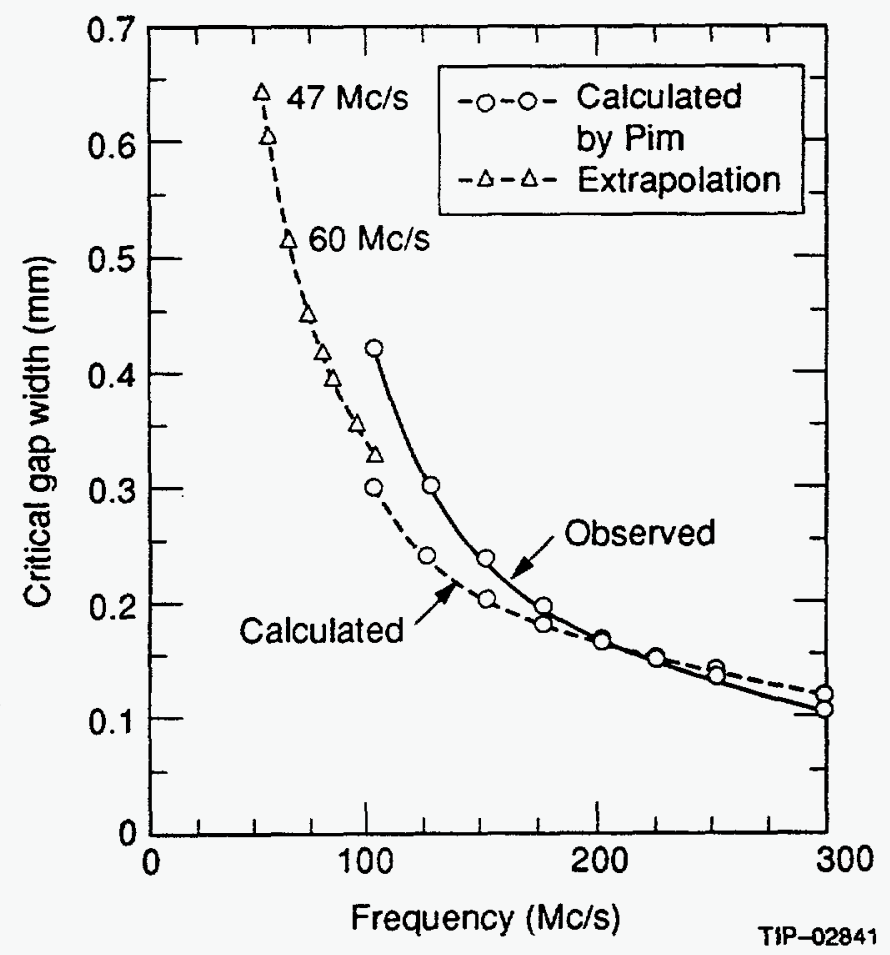

Figure 10. Variation of Critlcal Gap Width with Frequency (Calculated by Pim and Extrapolated).

\subsection{BREAKDOWN IN VACUUM}

Breakdown in vacuum cannot be explained by the above theory, which states that breakdown is caused by the ionization electrons, positive ions, and molecules through collisions; that is, unless there are gas molecules, no breakdown can occur. "When the pressure and gas density in a system are so low that the electron mean free path is much larger than the spacing of conductors, electron multiplication by impact ionization of the gas molecules cannot take place."7 Meek also agrees on this point. 5

In reality, breakdown is observed at all times in vacuum if the field intensity is very high. Sparks appear in good vacuum $\left(10^{-6}-10^{-7} \mathrm{~mm} \mathrm{Hg}\right)$ when the field intensity. is $100-1000 \mathrm{kV} / \mathrm{cm}$.

In the absence of gas ionization, breakdown can occur from the electrodes' effects. "Milikan, Eyring, and Mackeowen studied these sparks [in vacuum $10^{-6}-10^{-7} \mathrm{~mm} \mathrm{Hg}$ ] and came to the conclusion that they resulted from intense localized electron emission at the surfaces of electrodes due to the 'pulling of electrons out of metal." "6 In fact, there is a protrusion or an irregularity on the surface of the electrode where the field intensity is much higher than that at any other point. At this point, the electron can get out of the surface forming the current; the local temperature rises, so the gas forms a film at the electrode, and the metal point vaporizes. Then there are enough gas and metal vapors to be ionized, forming the path for the breakdown. After the breakdown, the irregularity is destroyed. Another irregularity with the higher breakdown potential will be the next target. Consequently, electrodes that have been flashed in vacuum many times will have higher breakdown potential. In other words, the smoother the surfaces of the electrodes, the higher the breakdown potential.

At first, it was believed that high field intensity reduced the potential barriers of metal atoms so that the electrons were liberated. If this were true, the effect would have to be temperature-dependent. But experiments conducted above $1500^{\circ} \mathrm{C}$ showed that the results were independent of temperature. Later a theory was developed in which all electrons, including the degenerate ones, can leak out under the influence of the external high field. These electrons consist of not only the ones in the outermost band, but the degenerate ones in the inner bands as well. Therefore, it was concluded that the results are not temperaturedependent. 6 


\subsection{CONCLUSION}

In summary, the critical gap may be determined at any desired frequency. The two frequencies of interest are $47 \mathrm{MHz}$ and $60 \mathrm{MHz}$, at which the estimated critical gaps are $0.64 \mathrm{~mm}$ and $0.512 \mathrm{~mm}$, respectively, and the estimated breakdown potentials are $2066 \mathrm{rms} \mathrm{V}$ and $1728 \mathrm{rms} \mathrm{V}$, respectively. It is suggested that at gaps smaller than the critical gap, the value of breakdown stress should be 10-15\% lower than the static value. For gaps much longer than the critical gap, the value of the breakdown stress should be $29 \mathrm{kV} / \mathrm{cm}^{3}$

Since the breakdown in vacuum originates from irregularities on the surfaces, these irregularities are dominant factors. Moreover, the vacuum breakdown cannot be explained by the theory of ionization due to collisions. The effect of frequency on the breakdown in this case, if any, is of secondary importance. 



\section{REFERENCES}

1. M. Abdel-Salam, "Electrical Breakdown of Gases," High Voltage Engineering: Theory and Practice, ed. M. Khalifa, New York and Basel: Marcel Dekker, Inc., 1990, pp. 93-121.

2. L. E. Reukema, "The Relation Between Frequency and Spark-over Voltage in a Sphere-gap Voltmeter," Transactions A.I.E.E., pp. 38-49.

3. J. A. Pim, "The Electrical Breakdown Strength of Air at Ultra-High Frequencies," I.E.E. Journal, 22 November 1948, Section: Radio, pp. 117-129.

4. Berthold Gänger, Der Electrische Durchschlag von Gasen, trans. by Jim Curbow, Berlin: SpringerVerlag, 1953.

5. J. M. Meek, and J.D. Craggs, Electrical Breakdown of Gases, Oxford: Clarendon Press, 1953.

6. B. Leonard Leob, Fundamental Processes of Electrical Discharge in Gases, New York: John Wiley \& Son, Inc. 1939.

7. H. Wayne Beaty, Electrical Engineering Material Reference Guide, New York: McGraw Hill, 1990. 

C THIS PROGRAM DETERMINES THE EQUATION OF A STRAIGHT LINE

C REPRESENTING A NUMBER OF EMPIRICAL DATA.

C

C VARIABLES USED.

INTEGER $N$, I, INDEX

REAL SUMX, SUMY, SUMXY, SLOPE, B, RESSUM,

$+\quad X(20), Y(20), \operatorname{EST} Y(20), \operatorname{RES}(20), \operatorname{RESMAX}$

C

C

C NUMBER OF DATA USED

$\operatorname{READ}(1, *) N$

C PRINT THE HEADING AND THE COLUMNS OF THE OUTPUT

WRITE $(5,100)$ 'THE LEAST SOUARES LINE FITTING'

100 FORMAT(', '.20X.A26)

WRITE $\left(5,200^{\circ}\right)$ NUMBER OF EXPERIMENTAL POINTS: $\because N$

200 FORMAT(' 0 ',20X,A33, I2)

WRITE( 5.300) 'EXPERIMENTAL', 'EXPERIMENTAL'.

$+$ 'ESTIMATED $Y$ ', 'RESIOUAL'

300 FORMAT( 'D',A12,13X,A12,13X,A9,15X,A9)

WRI TE $(5,400)$ ' $X$-VALUE', ' $Y$-VALUE', ' $Y$-VALUE'

400 FORMAT ( $1 X, A 7,18 X, A 7,18 X, A 7)$

C

C READ THE EMPIRICAL DATA INTO ARRAYS $X(I), Y(I)$

$\operatorname{READ}(1, *)(X(I), Y(I), I=1, N)$

C FIND THE EQUATION OF THE STRAIGHT LINE $Y=A * X+B$

$C$ A IS THE SLOPE; $B$ IS THE Y-INTERCEPT

C SUMX $=X_{1}+X_{2}+\ldots \ldots+X N$

C SUMY $=Y_{1}+Y_{2}+\ldots \ldots+Y N$

C SUMXY $=X 1 * Y 1+X 2 * Y Z+\ldots \ldots+X N * Y N$

c SUMSOX $=X 1 * X 1+X 2 * X 2+\ldots \ldots+X N * X N$

C SLOPE $A=$ ( SUMX*SUMY - N*SUMXY )/(SUMX*SUMY - N*SUMSOX)

C $Y$-INTERCEPT $B=$ ( SUMY - SLOPE $* S U M X) / N$

SUMX $=0.000$

SUMY $=0.000$

SUMXY $=0.000$

SUMSQX $=0.000$

DO 500 I $=1, N$

SUMX $=$ SUMX $+X(I)$

SUMY $=$ SUMY $+Y(I)$

SUMXY $=$ SUMXY $+X(I) * Y(I)$

500

CONT INUE

SUMSQX $=$ SUMSQX $+X(I) * * 2$

SLOPE $=$ ( SUMX*SUMY - FLOAT(N)*SUMXY )

$+$

( SUMX**2 - FLOAT $(N) *$ SUMSOX)

$B=($ SUMY - SLOPE $*$ SUMX ) / FLOAT(N)

C COMPUTE THE RESIOUAL OF EACH POINT, WHICH IS THE

C DIFFERENCE BETWEEN THE ACTUAL AND ESTIMATED VALUES OF $Y$

RESSUM $=0.000$

DO 600 I $=1, N$

ESTY( I ) = SLOPE $* X(I)+B$

RES( I ) $=Y(I)-E S T Y(I)$

600 CONTINUE

RESSUM $=$ RESSUM + RES( $I) * * 2$

C FIND THE LEAST ACCURATE POINTS WHOSE RESIDUALS ARE MAXIMUM.

C INDEX INDICATES THE SUBSCRIPTS OF THESE POINTS IN RES( I) 


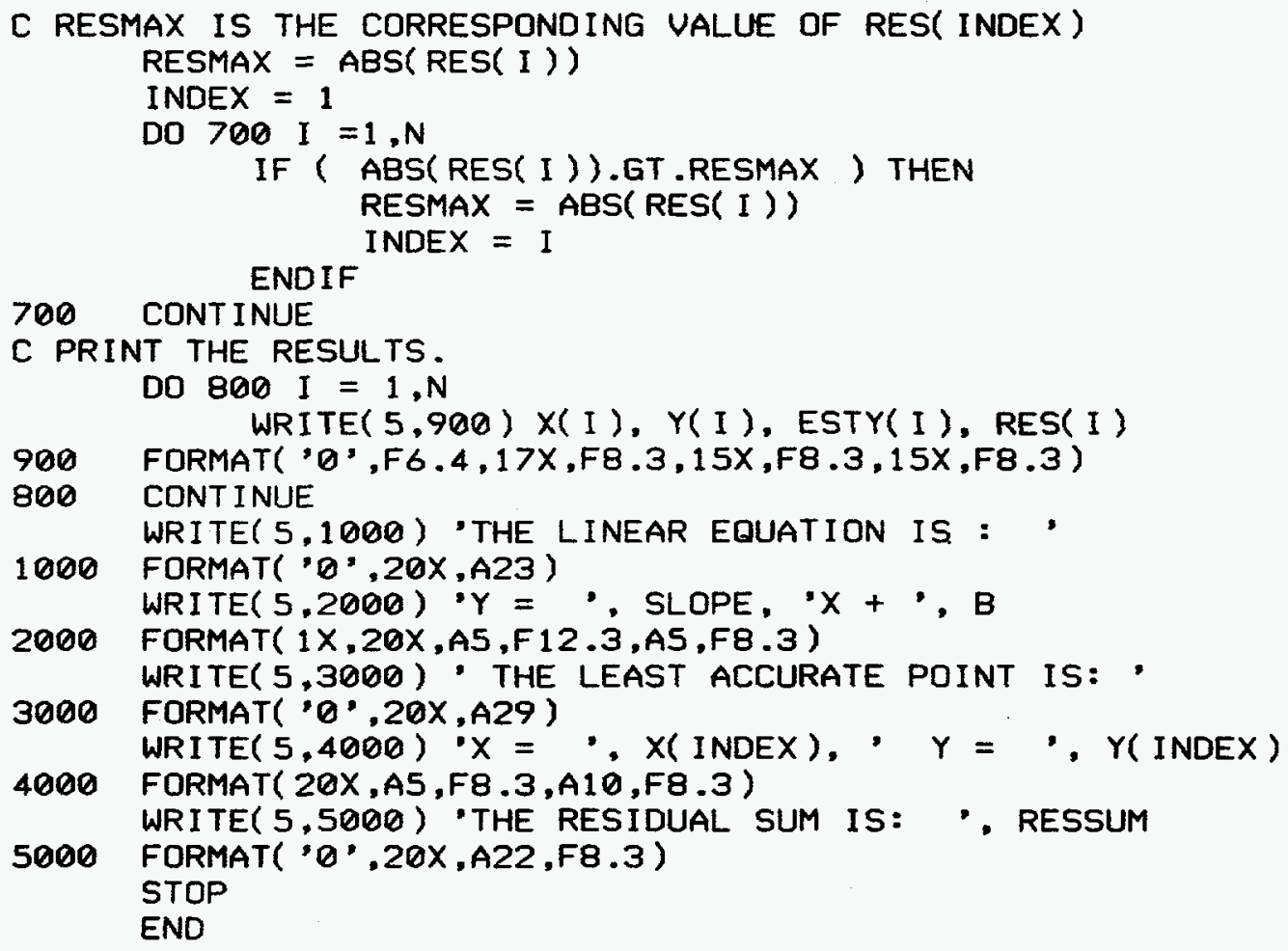


THE LEAST SQUARES LINE FIT

NUMBER OF EXPERIMENTAL POINTS: 8

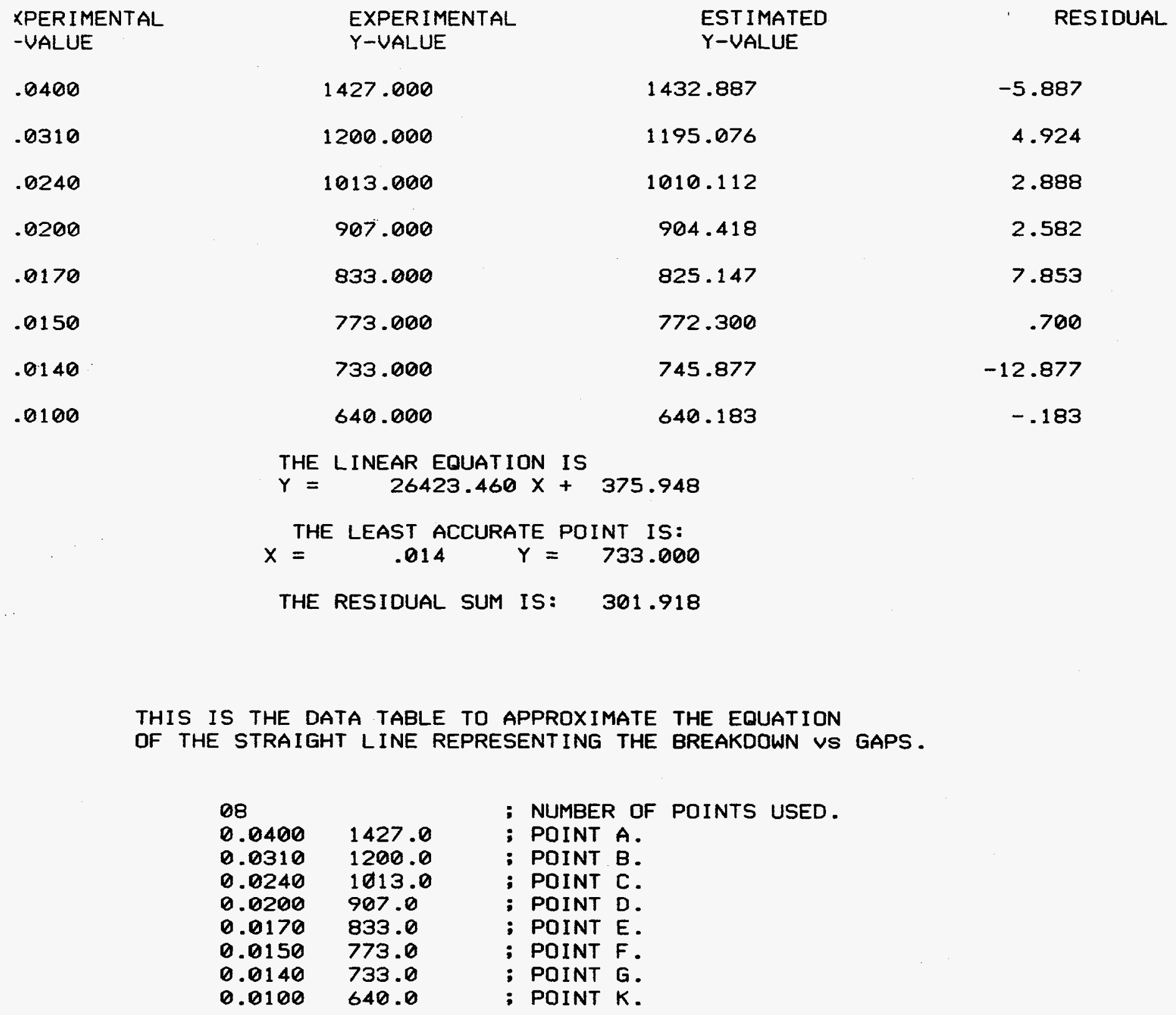


THE LEAST SQUARES LINE FIT

NUMBER OF EXPERIMENTAL POINTS: 8

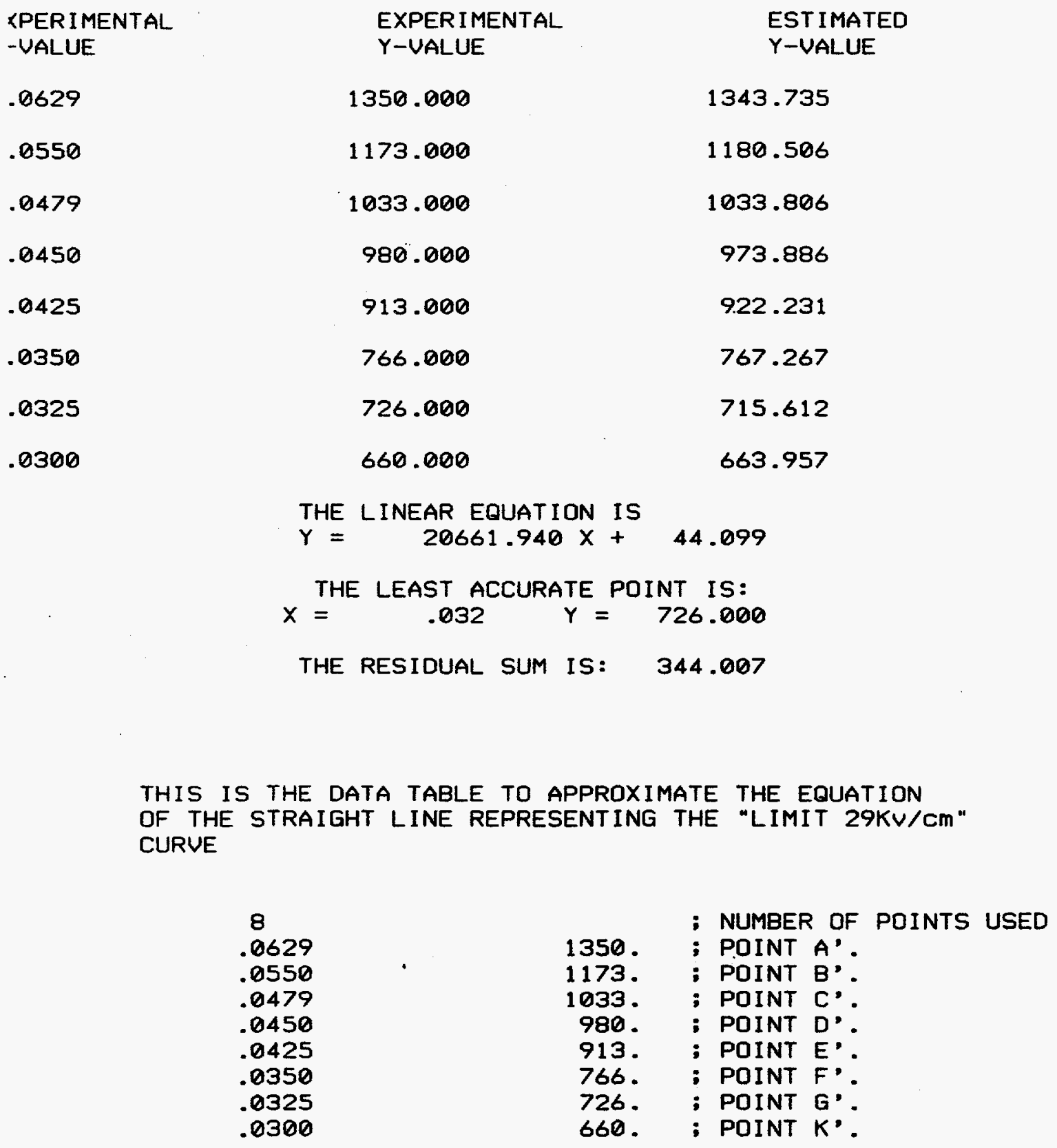


THE LEAST SQUARES LINE FIT

NUMBER OF EXPERIMENTAL POINTS: 6

XPERIMENTAL

-VALUE

.0400

.0375

.0350

.0325

.0300

.0275
EXPERIMENTAL

Y-VALUE

1573.000

1493.000

1440.000

1367.000

1300.000

1220.000
EST IMATED Y-VALUE

1571.476
1502.419
1433.362
1364.305
1295.248
1226.191

1571.476

1.524

$-9.419$

6.638

2.695

4.752

$-6.191$

THE LINEAR EQUATION IS

$Y=27622.770 X+466.565$

THE LEAST ACCURATE POINT IS:

$X=\quad .038 \quad Y=1493.000$

THE RESIDUAL SUM IS: 203.277

THIS IS THE DATA TABLE TO APPROXIMATE THE EQUATION OF THE STRAIGHT LINE REPRESENTING THE SOHZ- BREAKDOWN CURVE.

$\begin{array}{lll}6 & & \text {; NUMBER OF POINTS USED. } \\ 0.04 & 1573 . & \text {; POINT } 1 \\ 0.0375 & 1493 . & \text {; POINT } 2 \\ 0.0350 & 1440 . & \text {; POINT } 3 \\ 0.0325 & 1367 . & \text {; POINT } 4 \\ 0.03 & 1300 . & \text {; POINT } 5 \\ 0.0275 & 1220 . & \text {; POINT } 6\end{array}$


C This program computes the CRITICAL GAP verssus FREQUENCY

$C$ using the iteration method.

REAL E, El, V, F, G, W, K, A, B, P, PI

$C$ Guess the initial value of breakdown stress $E$

WRITE $(*, *)$ 'ENTER THE VALUE OF $E$ '

$\operatorname{READ}(*, *) \mathrm{E}$

WRITE $(*, *)$ 'ENTER THE VALUE OF F'

READ $(*, *) \quad F$

$K=3.9 E+5$

$A=1.58 \mathrm{E}-5$

$B=1.33 \mathrm{E}-2$

$P=760$.

$P I=3.1416$

C the first iteration

$\mathbf{W}=2 * \mathrm{PI} * \mathrm{~F}$

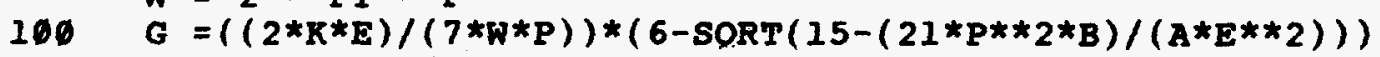

$V=26423.460 * G+375.948$

$E 1=V * 1.414 / G$

C Create the WHILE DO loop to compare values of guessed $\mathbf{E}$ and

c calculated one after an iteration cycle.

IF (ABS(EI-E).GT.0.01) THEN

$\mathbf{E}=\mathbf{E} 1$

GO TO 100

ENDIF

WRITE $(5, *)$ 'THE APPLIED FREQUENCY IN HZ:,$F$

WRITE $(5, *)$ 'THE CRITICAL GAP IN CM:', G

WRITE $(5, *)$ 'THE BREAKDOWN VOLTAGE IN VOLT RMS: ', V

WRITE $(5, *)$ 'THE PEAK BREAKDOWN STRESS IN VOLT/CM ', E STOP

END 
THE APPLIED FREQUENCY IN HZ: 47000000.0000000

THE CRITICAL GAP IN CM: $6.397086 \mathrm{E}-002$

THE BREAKDOWN VOLTAGE IN VOLT RMS:

THE PEAK BREAKDOWN STRESS IN VOLT/CM

2066.2800000

45672.6600000

THE APPLIED FREQUENCY IN HZ: 50000000.0000000

THE CRITICAL GAP IN CM: $6.042679 E-002$

THE BREAKDOWN VOLTAGE IN VOLT RMS:

THE PEAK BREAKDOWN STRESS IN VOLT/CM

1972.6330000

46160.0400000

THE APPLIED FREQUENCY IN HZ: 60000000.0000000

THE CRITICAL GAP IN CM: $5.118431 \mathrm{E}-002$

THE BREAKDOWN VOLTAGE IN VOLT RMS:

$\begin{array}{lll}\text { THE BREAKDOWN VOLTAGE IN VOLT RMS: } & 1728.4150000 \\ \text { THE PEAK BREAKDOWN STRESS IN VOLT/CM } & 47748.5800000\end{array}$

THE APPLIED FREQUENCY IN HZ: 70000000.0000000

THE CRITICAL GAP IN CM: $4.459188 \mathrm{E}-002$

THE BREAKDOWN VOLTAGE IN VOLT RMS: 1554.2200000

THE PEAK BREAKDOWN STRESS IN VOLT/CM $\quad 49284.0200000$

THE APPLIED FREQUENCY IN HZ: 75000000.0000000

THE CRITICAL GAP IN CM: 4.195645E-002

THE BREAKDOWN VOLTAGE IN VOLT RMS:

THE PEAK BREAKDOWN STRESS IN VOLT/CM

1484.5830000
50032.8300000

THE APPLIED FREQUENCY IN HZ: 80000000.0000000

THE CRITICAL GAP IN CM: $3.965079 \mathrm{E}-002$

THE BREAKDOWN VOLTAGE IN VOLT RMS: 1423.6590000

THE PEAK BREAKDOWN STRESS IN VOLT/CM

THE APPLIED FREQUENCY IN HZ: 90000000.0000000

THE CRITICAL GAP IN CM: $3.580752 E-002$

THE BREAKDOWN VOLTAGE IN VOLT RMS: 1322.1070000

THE PEAK BREAKDOWN STRESS IN VOLT/CM 52208.5400000

THE APPLIED FREQUENCY IN HZ: $1.000000 \mathrm{E}+008$

THE CRITICAL GAP IN CM: $3.273082 \mathrm{E}-002$

THE BREAKDOWN VOLTAGE IN VOLT RMS:

THE PEAK BREAKDOWN STRESS IN VOLT/CM

1240.8100000

53604.0600000 